Или по схеме:

$$
\begin{aligned}
& \mathrm{CO}^{2+}+\gamma^{\prime} \stackrel{\text { возбужденное состояние }}{\longrightarrow} E_{1}+\mathrm{Co}^{2+}+n^{\circ} \stackrel{\text { распад нейтрона }}{\longrightarrow} \\
& E_{1}+\mathrm{Co}^{2+}+p^{+}+e^{-}+\tilde{v}_{e} \stackrel{\text { новое основное состояние }}{\longrightarrow} \gamma^{\prime \prime}+N i^{2+}+\tilde{v}_{e}
\end{aligned}
$$

Заключение. В результате ядерных реакций в ядре Земли возникают протоны и нейтроны, которые захватываются атомами материнской матрицы и переводят номер элемента на единицу больше в таблице Менделеева. Так формируются атомы примеси.

$$
* * *
$$

1. Gait R. I., Dumka D. Morphology of pyrite from the Nanisivik mine, Baffin Island, Northwest Territories. // The Canadian Mineralogist. - 1986. - V. 24, P. 685-688.

2. Larocque A. C. L., Hodgson C. J., Cabri L. J., Jackman J. A. Ion-microprobe analysis of pyrite, chalcopyrite and pyrrhotite from the Mobrun VMS deposit in northwestern Quebec: evidence for metamorphic remobilization of gold, // The Canadian Mineralogist. - 1995. - V. 33. - P. 373-388.

3. Carlson R. W. (2015) Planetary science: A new recipe for Earth formation. doi:10.1038/520299a

4. Onufrienok V.V., Some Comments on Pyrite's Structure// Biomedical Journal of Scientific \& Technical Research, 2019, V. 19, iss.4, 14443-14444.

5. Onufrienok V.V., Broekmans M.A.T.M. Analysis of Impurity Density in the Structure of Arsenopyrite of the Panimba Deposit. In: Dong F. (eds) Proceedings of the 11th International Congress for Applied Mineralogy (ICAM). Springer Geochemistry/Mineralogy. Springer, Cham, 2015, p. 325-334

6. Онуфриенок В.В., Чжан А.В. Точечные дефекты и их влияние на физические свойства кристаллов », КГАУ, Красноярск, с. 148, 2018

7. Pearson WB The crystal chemistry and physics of metal and alloys. Wiley, New York, p. 826 (1972)

8. Rickard D., Luther G. Chemistry of Iron Sulfides // Chem. Rev. - 2007. - V.107. - p. 514-565

9. Сазонов А.М., Звягина Е.А., Кривопутская Л.М., Свердлова В.Г., Леонтьев С.И. Структурные и химические неоднородности пирита Саралинского месторождения (Кузнецкий Алатау). Геология и геофизика. 1992. Т. 33. С. 87-94.

10. Vaughan DJ, Craig JR (1978) Mineral chemistry of metal sulfides. Cambridge University Press, Cambridge, p. 493.

11. Hem S. R., Makovicky E., Gervilla F. Compositional trends in Fe, Co, and Ni sulfarsenides and their crystal-chemical implications: results from the Arroyo de la Cueva deposits, Ronda peridotite, southern Spain. // The Canadian Mineralogist. —2001. -V. 39. - P. 831-853.

\title{
Сверчков Д.Ю. \\ Индивидуальная образовательная траектория курсанта (слушателя) в условиях смешанного обучения в нелинейном образовательном пространстве
}

610 ЦБП и ПЛС

(Россия, Иваново)

doi: $10.18411 / s r-10-06-2021-50$

\section{Аннотация}

В целях совершенствования качества образования необходимо прогнозировать полноценное развитие личности в современной системе обучения, что становится возможным в нелинейном образовательном пространстве. Индивидуальная образовательная траектория курсанта (студента) - это его личный, индивидуальный путь, который определяется совместно с преподавателем при учете мотиваций, способностей, психофизиологических особенностей обучающегося. Смешанная модель обучения позволяет сочетать инновационные технические достижения цифрового обучения и проверенный годами опыт традиционного взаимодействия студентов и преподавателя в рамках аудиторных занятий. Внедрение смешанного обучения в нелинейное пространство военного вуза позволит наиболее эффективно выстраивать индивидуальную образовательную траекторию курсанта.

Ключевые слова: индивидуальная образовательная траектория, смешанное обучение, нелинейное образовательное пространство, дистанционное обучение 


\section{Abstract}

In order to improve the quality of education, it is necessary to predict the full development of the individual in the modern education system. This possibility exists when teaching in a non-linear educational space. The individual educational trajectory of a cadet (student) is his personal, individual path, which is determined together with the teacher, taking into account the motivations, abilities, psychophysiological characteristics of the student. The Blended Learning model is a combination of innovative technical advances in digital learning and the experience of traditional student-teacher interactions in the classroom. To effectively build an individual educational path for a cadet, it is necessary to introduce Blended Learning into the nonlinear space of a military university.

Keywords: individual educational path, Blended Learning, non-linear educational space, Distance Learning

Современный мир движется очень быстрыми темпами, успешное существование человека в нём возможно тогда, когда он может расти, развиваться, изменяться, подстраиваться и перестраиваться, быть супергибким в постоянно меняющемся пространстве. Подчеркнём, что простая линейная и односторонняя модель в системе образования уже является недостаточной. В этой связи в системе образования идет поиск альтернативы традиционному линейному подходу.

Принцип нелинейности предполагает нелинейный стиль мышления, неоднозначность теоретических построений, подстройку под сложившиеся условия (события последнего года наглядно доказали нам это). Думается, что человеку, даже находящемуся внутри нелинейного пространства, очень сложно представить себе всё его многообразие, его структуру, состав.

Поскольку нелинейность характеризуется связями различного рода (между представителями управленческого сообщества, между учебными заведениями, между преподавателями, между преподавателями и обучающимися, между субъектами образования и внешней средой и др.), самым главным элементом нелинейной модели образовательного пространства является человек, его развитие и саморазвитие, самодвижение, самообразование.

Нелинейная модель в образовании - такая модель, в которой происходит развитие творческой индивидуальности, использование внутреннего потенциала человека, развитие профессиональных и личностных качеств как обучающегося, так и преподавателя [3].

Кажется, что нелинейность учебных стратегий курсантов (студентов) должна, прежде всего, базироваться на вариативности форм повышения уровня знаний, на академической мобильности, которые воплощаются в способности и возможности найти свой нестандартный путь развития, как специалиста.

Представляется необходимым также отметить, что одним из важнейших составляющих нелинейной системы является совместное научное творчество курсанта (студента) и преподавателя. Именно оно пробуждает неподдельный интерес к учебе, реальную мотивацию к научно-образовательной деятельности.

Очевидно, что именно знание объединяет индивидуальную образовательную траекторию курсанта (студента) и профессиональную траекторию преподавателя.

Бесспорно, что каждый подход, как и каждая отрасль знания, имеет свой понятийный аппарат. Индивидуальная образовательная траектория, индивидуальный образовательный маршрут, индивидуальная образовательная программа - новые активно разрабатываемые в педагогике высшей школы понятия, которые являются, на наш взгляд, базовыми элементами образовательного пространства высшей школы. 
Индивидуальная образовательная траектория курсанта (студента) - это его личный, индивидуальный путь, который определяется совместно с преподавателем при учете мотиваций, способностей, психофизиологических особенностей обучающегося.

Хочется подчеркнуть, что именно в нелинейном образовательном пространстве создаются условия, при которых обучающийся имеет возможность самостоятельного построения индивидуальной образовательной траектории при прохождении им индивидуального маршрута в рамках своей образовательной программы [1].

В связи с тем, что развитие науки и общества не стоит на месте, переход к цифровым технологиям происходит и в образовательной среде. Начавшая формироваться сравнительно недавно как средство обучения цифровая образовательная среда дает возможность проводить смешанное обучение (Blended Learning) курсантов (студентов). Данный метод обучения позволяет сочетать инновационные технические достижения цифрового обучения и проверенный годами опыт традиционного взаимодействия студентов и преподавателя в рамках аудиторных занятий [4].

В настоящее время известны шесть основных моделей организации смешанного обучения. Исходя из предмета, потребностей и уровня знаний и развития навыков, и умений обучающихся, преподаватель может выбрать подходящую данной группе обучающихся модель из следующих:

- поддержка очного обучения (face-to-face driver) - преподаватель лично дает основной объем учебной информации на занятиях, по мере необходимости внедряя онлайн обучение как вспомогательное; на занятиях также регулярно организуется работа обучающихся на компьютерах;

- ротационная модель (rotation model) - обучение осуществляется путем поочередной смены традиционного обучения в аудитории с самостоятельным онлайн обучением;

- гибкая модель (flex model) - по большей части используется онлайн платформа, а преподаватель при необходимости поддерживает обучающихся, время от времени работая с небольшими группами или с отдельными обучающимися;

- онлайн лаборатория (online lab) - для передачи содержания всего учебного курса на занятиях в аудитории используется онлайн платформа, все обучение происходит при непосредственном участии преподавателя;

— модель «Смешай сам» (self-blend model) - обучающийся самостоятельно решает, чем ему следует заняться более углубленно и, соответственно, какую часть учебного курса дополнить онлайн занятиями;

- поддержка онлайн обучения (online driver model) - модель в основном предполагает обучение онлайн через платформу и удаленный контакт с преподавателем, к которым при необходимости могут быть добавлены очные занятия и встречи с преподавателем.

Компьютерные технологии позволяют создать единое рабочее пространство для работы в сети. Примером могут служить различные системы управления обучением (Learning Management System), самой популярной из которых в гражданских вузах является на сегодняшний день Moodle.

Moodle - удобная, бесплатная, платформа для обучения. Студенты обучаются в электронном университете на этой платформе. В личном кабинете каждого студента есть список курсов, которые ему необходимо изучить. Если задание нужно выполнить срочно, то студенту приходит необходимое оповещение на электронную почту. 
Дистанционное обучение - реальность сегодняшнего дня. Хотелось бы подробнее остановиться на том моменте, как можно формировать индивидуальную образовательную траекторию на базе электронного курса в Moodle.

Приведём пример электронного курса в гражданском вузе. Курс русского языка для студентов иностранцев (исторический факультет) спланирован определенным образом. Работа в семестре включает в себя три большие одинаково структурированные темы. В рамках одной из них студенты знакомятся с одной грамматической темой и отрабатывают её на материале упражнений и разных типах текстов. Знакомство с грамматической темой начинается с просмотра презентации с пояснениями о данном грамматическом явлении, также есть ссылка на объяснение этой темы в ролике на уoutube (с переводом на родной язык студента). Далее даются грамматические упражнения (например, сначала на образование формы, затем на ее функционирование). Затем дается тест для контроля знаний. Следующий шаг изучение грамматического явления на материале сначала проблемного текста (проблемы демографии), потом - на материале языка специальности - текст «Восстание декабристов». Студенты обучаются навыкам конспектирования, одновременно отрабатывая грамматические явления.

Раздел «Самостоятельная работа» студента включает в себя упражнения по грамматике, тест, а также материалы для работы с фильмом «Звезда пленительного счастья» (В. Мотыль, 1975), ссылку на фильм.

Каждый студент в рамках данной темы должен обязательно выполнить два грамматических теста и ответить пересказ двух текстов с применением ВВВ (BigBlueButton). Но каждый студент выбирает свой путь, свою траекторию следования в рамках данной темы. Для плохо говорящего студента необходим последовательный путь прохождения каждого задания и, быть может, многократное повторение (просмотр ролика с объяснением на родном языке необходим). Хорошо говорящий студент после беглого просмотра презентации может сразу приступить к выполнению упражнений. Мотивированный студент обязательно найдет время для просмотра фильма и материалов к нему. Учитывая разную степень владения языком, очевидно, что для разных студентов время, затраченное на работу с текстом и его последующий пересказ, тоже будет разным. Так, например, к одному и тому же учебному тексту можно предложить разные по сложности задания. Слабые студенты имеют возможность потренироваться сначала на более простых заданиях, а сильные студенты могут сразу перейти к заданиям повышенной сложности и пересказу.

Доступность и наглядность материала позволяет студенту многократное повторение материала, что является очень важным при обучении иностранному языку. Свою роль играет и гибкий график обучения.

Резюмируя вышесказанное, приходим к выводу о том, что использование цифрового обучения облегчает студенту процесс приобретения знаний, позволяет формировать свою индивидуальную образовательную траекторию.

Становясь востребованной и действенной при изучении иностранного языка, смешанная модель требует от преподавателя серьёзной подготовки и ставит перед ним несколько задач. Во-первых, это касается учебного материала: речь здесь идет о его правильной организации. Основная задача преподавателя заключается в том, что он должен четко знать, какой материал будет изучаться в аудитории, а какой, в силу несложности рассматриваемых проблем, можно предоставить для изучения в дистанционной форме. Преподавателю необходимо учитывать степень сложности материала и время, которое понадобится студентам для выполнения заданий и упражнений. 
Во-вторых, преподаватель должен четко представлять организацию учебного процесса. В его поурочном плане должно быть прописано, какие виды деятельности будут осуществляться на занятиях в аудитории и дистанционно, какие виды контроля будут применены.

Каждый учебный элемент может включать в себя базовую часть и вариативную, формируемую в соответствии с образовательными потребностями и возможностями обучающихся.

Как известно, военные вузы отличаются своей корпоративностью и спецификой организации процесса обучения. Данные отличия обусловлены невозможностью полного открытого информационного контакта с внешней средой, вследствие закрытости некоторой части данных о военном деле, строгим распорядком дня, обособленностью территорий, предназначенных для обучения курсантов и слушателей и т.д. Однако в последнее время цифровые технологии все активнее начинают внедряться в образовательную среду военных вузов [2]. Примером могут послужить появившиеся сравнительно недавно электронные учебники. Данные цифровые средства не просто являются аналогами бумажных носителей информации, в них содержатся элементы самоконтроля, возможность выбора удобной для восприятия и усвоения формы представления учебного материала, алгоритмы планирования дальнейшего хода обучения и др. Вследствие создания и развития цифровой образовательной среды в военных вузах, существует реальная перспектива создания собственных цифровых платформ для смешанного обучения курсантов и слушателей. Достаточное большое количество времени, выделяемое в распорядке дня военного вуза для самостоятельной подготовки, может более рационально расходоваться вследствие внедрения такого вида обучения. Положительный эффект от этого будет проявляться не только в повышении качества обучения курсантов и слушателей, но и в освобождении рабочего времени преподавателей и наставников для более качественной подготовки к предстоящим очным занятиям в аудитории и для других научных потребностей. Для офицеров же, более того, самостоятельная подготовка является основным видом подготовки при службе в строевых воинских частях. Поэтому очень важно направить этот ресурс в нужное русло, на повышение качества образования.

Подводя итог, необходимо сказать, что внедрение смешанного обучения в нелинейном пространстве военного вуза позволит наиболее эффективно выстраивать индивидуальную образовательную траекторию курсанта (слушателя). Предполагается, что на начальном этапе нужно использовать первую из описанных выше моделей (поддержка очного обучения). Преподаватель при этом лично дает основной объем учебной информации на занятиях, по мере необходимости внедряя обучение на цифровой платформе как вспомогательное. На занятиях регулярно должна организовываться также работа обучающихся на компьютерах.

$$
* * *
$$

1. Бережная И. Ф. Педагогическое проектирование индивидуальной траектории профессионального развития будущего специалиста : монография. Воронеж : «Научная книга», 2012. - 219 с.

2. Гладких В.В., Сверчков Д.Ю. Цифровая образовательная среда как средство обучения курсантов по индивидуальной образовательной траектории. Перспективы науки. - 2019. - №5(116)с. - 237239

3. Зборовский Г. Е., Амбарова П. А. и др. Нелинейная модель российского высшего образования в макрорегионе: теоретическая концепция и практические возможности : монография под редакцией Г. Е. Зборовского. Екатеринбург : Гуманитарный ун-т, 2016. - 336 с.

4. Чайка Е. Ю. Проблемы и возможности реализации модели смешанного обучения иностранным языкам в вузе / Е. Ю. Чайка, Е. В. Куренкова // Эмиховские чтения : материалы V международной научно-практической конференции, Тюмень, 15-17 ноября 2017 г. - Тюмень : Агат, 2018. - С. $177-183$. 